\title{
Improved Composite Gel Electrolyte by Layered Vermiculite for Quasi-Solid-State Dye-Sensitized Solar Cells
}

\author{
Hongcai He, ${ }^{1}$ Shuangshuang Ren, ${ }^{1}$ Deting Kong, ${ }^{1}$ and Ning Wang ${ }^{1,2}$ \\ ${ }^{1}$ State Key Laboratory of Electronic Thin Films and Integrated Devices and School of Microelectronics and Solid-State Electronics, \\ University of Electronic Science and Technology of China, Chengdu 610054, China \\ ${ }^{2}$ Institute of Electronic and Information Engineering, University of Electronic Science and Technology of China, \\ Dongguan 523808, China
}

Correspondence should be addressed to Hongcai He; hehc@uestc.edu.cn

Received 12 March 2014; Accepted 30 March 2014; Published 22 April 2014

Academic Editor: Ke Sun

Copyright (C) 2014 Hongcai He et al. This is an open access article distributed under the Creative Commons Attribution License, which permits unrestricted use, distribution, and reproduction in any medium, provided the original work is properly cited.

A composite quasisolid electrolyte is prepared by adding a layered vermiculite (VMT) into the iodide/triiodide electrolyte including 4-tert-butylpyridine, which obviously improves the photovoltaic properties of quasisolid dye-sensitized solar cells (DSSCs). When adding $6 \mathrm{wt} \%$ VMT, the maximum photovoltaic conversion efficiency of $3.89 \%$ is obtained, which reaches more than two times greater than that without VMT. This enhancement effect is primarily explained by studying the Nyquist spectra, dark currents, and photovoltaic conversion efficiency.

\section{Introduction}

Dye-sensitized solar cells (DSSCs) have attracted an everincreasing attention since reported by O'Regan and Grätzel in 1991 [1] for its low-cost, environmental friendliness, and potential high conversion efficiency, which was considered to be a strong contender of the next-generation solar cells in the near future. Generally, a mainstream DSSC is composed of three main parts: a dye-adsorbed porous nanocrystalline $\mathrm{TiO}_{2}$ film supported on a transparent conducting glass as the photoanode, an organic liquid electrolyte, essentially containing an iodide/triiodide redox couple, and a platinized transparent glass substrate as the counter electrode. These three layers are sandwiched together. Electrolytes play an important role in the DSSCs as the charge exchange medium. The organic liquid electrolyte was commonly used in traditional DSSCs, which is associated with problems such as hermetic sealing of the cell, solvent volatilization and leakage, bad long-term stability, decomposing dye, and corroding $\mathrm{Pt}$ electrode.

Recently, many efforts have been made to overcome the above problems of traditional DSSCs with liquid electrolytes, and solid-state and quasi-solid-state DSSCs have been intensely studied with various approaches. Some novel technologies and materials including p-type semiconductors [2], organic and inorganic holes conductors [3], and polymer gel electrolytes [4,5] were used in new electrolytes to improve properties. Among them, polymer based quasisolid-state electrolytes are a very good choice for its high ionic conductivity, long-term stability, good interfacial filling properties, and inhibiting leakage, which commonly have a polymer and ionic liquid electrolytes containing dispersed nanocomponents. Some ceramic nanoparticles such as $\mathrm{SiO}_{2}$ [6], $\mathrm{TiC}$ [7] and $\mathrm{TiN}$ [8] were added into ionic liquidsbased electrolytes for DSSCs, and an enhanced conversion efficiency was obtained. In our previous work $[9,10]$, some layered materials such as $\alpha$-zirconium phosphate and $\mathrm{Mg}-\mathrm{Al}$ hydrotalcite were added into the iodide/triiodide ionic liquid to prepare quasi-solid-state electrolytes, which obviously improves the photovoltaic properties of quasisolid DSSCs. Vermiculite (VMT) is not only a layered mica-type silicate but is also with a large surface area and strong absorptive capacity and has often been studied for the preparation of composites $[11,12]$. In this paper, a new composite gel polymer electrolyte was prepared by adding vermiculite (VMT) powder into iodide-based liquid electrolyte with the addition of 4-tert-butylpyridine (TBP), propylene carbonate (PC), and poly (ethylene oxide) (PEO-600,000). 


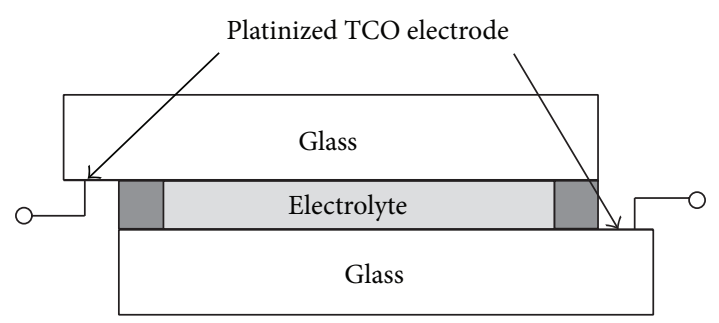

FIGURE 1: Schematic diagram of the experimental thin-layer cell configuration employed for the electrochemical measurements.

The electrochemical properties of the composite electrolyte were analyzed systematically by testing Nyquist diagram, and a typical DSSC was packaged with the new quasi-solid-state composite electrolyte to measure photovoltaic properties.

\section{Experimental}

2.1. Preparation of VMT and Composite Gel Polymer Electrolyte. The starting VMT was supplied by Bright Mining Co. (Shanghai, China). After VMT was ball-milled for $6 \mathrm{~h}$ in the solvent of deionized water, the ultrasonic irradiation method reported by Nguyen et al. [13] was used to prepare the layered vermiculite (VMT) powders.

Then, VMT powders with the contents of $0 \mathrm{wt} \%, 3 \mathrm{wt} \%$, $6 \mathrm{wt} \%, 9 \mathrm{wt} \%$, and $12 \mathrm{wt} \%$, relative to the weight of TBP, were added to the iodide-based gel polymer electrolyte prepared according to [14], which contained $0.5 \mathrm{M} \mathrm{LiI}, 0.05 \mathrm{M} \mathrm{I}_{2}$, $6 \mathrm{~mL}$ PC, 0.5 M TBP, 0.4 g PEO-600,000, and acetonitrile solvent. After stirring strongly for $72 \mathrm{~h}$ at $80^{\circ} \mathrm{C}$, the composite gel polymer electrolytes including layered VMT were obtained.

\subsection{Testing Device and Characterization Method. X-ray} diffraction (XRD Rigaku D/max-RB) with CuKa radiation was used for phase analysis of the powders under $40 \mathrm{kV}$ and $30 \mathrm{~mA}$. Scanning electron microscopy (SEM, INSPECTF FEI, Netherlands) was used to observe the micrographs. Simple thin-layer cells were manufactured to measure AC impedance according to [15]. The cell was made up of two identical platinized TCO-coated glass substrates separated by Surlyn thermal packaging adhesive and filled with the composite electrolyte with VMT additives, as shown in Figure 1. The active area of the electrodes was about $0.16 \mathrm{~cm}^{2}$ and the distance between the electrodes was about $25 \mu \mathrm{m}$. Electrochemical impedance spectra (EIS) were obtained by using $\mathrm{CHI660c}$ electrochemical analyzer $(\mathrm{CH}$ Instrument Co., ltd. China). Sinusoidal perturbations of $10 \mathrm{mV}$ at frequencies from $0.01 \mathrm{~Hz}$ to $100 \mathrm{kHz}$ with zero bias potential were applied on thin-layer cells with a two-electrode mode as shown in Figure 1. In order to study the photovoltaic properties of the DSSCs with the composite electrolytes containing VMT, quasisolid DSSCs were packaged according to the previous published procedures $[9,10]$ from dye-coated $\mathrm{TiO}_{2}$ film photoanodes, counterelectrodes (500 nm thick, $\mathrm{Pt}$ ), and composite gel polymer electrolytes containing VMT. Photovoltaic properties were measured at $100 \mathrm{~mW} \mathrm{~cm}^{-2}$ light intensity under AM 1.5 irradiation of xenon lamp, while the

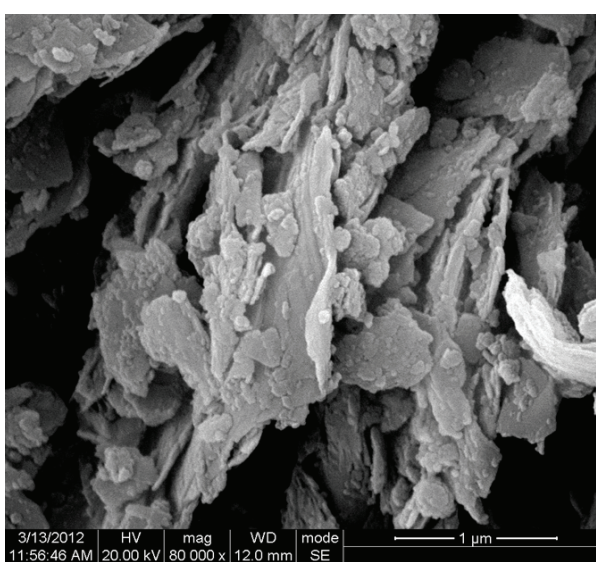

Figure 2: SEM micrograph of VMT powder.

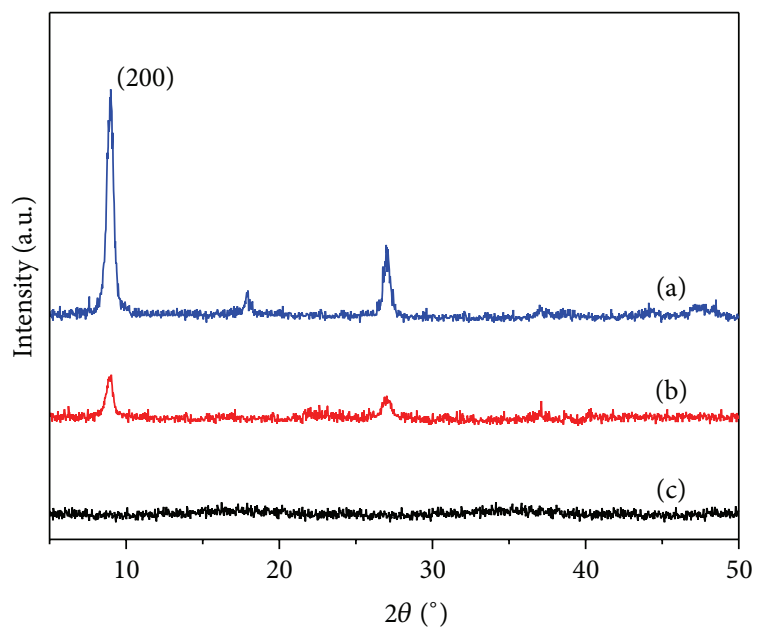

Figure 3: X-ray diffraction patterns of (a) VMT powder, (b) the composite electrolyte membrane with $6 \mathrm{wt} \% \mathrm{VMT}$, (c) the composite electrolyte membrane with $0 \mathrm{wt} \% \mathrm{VMT}$.

dark current density is measured in dark. All measurements were carried out at room temperature.

\section{Results and Discussion}

3.1. Analysis of VMT Powders. Figure 2 shows a SEM micrograph of VMT powders, and the layered structure with a nanoscale layer thickness can be observed. X-ray diffraction patterns of the prepared VMT powder and composite electrolytes are shown in Figure 3. As shown in Figure 3(a), the prepared VMT powders are well-crystallized with the strongest diffraction peaks at $8.96^{\circ}$, indexed as (200) peak [13]. After $6 \mathrm{wt} \% \mathrm{VMT}$ additive was mixed into iodine-based PEO electrolyte and coated on the photoanode thin film, the (200) peak was still detected in the obtained electrolyte membrane as shown in Figure 3(b).

3.2. The Influence of VMT on the Conductivity. The Nyquist spectra of thin-layer cells with composite gel iodide-based electrolytes containing different contents of VMT are shown 


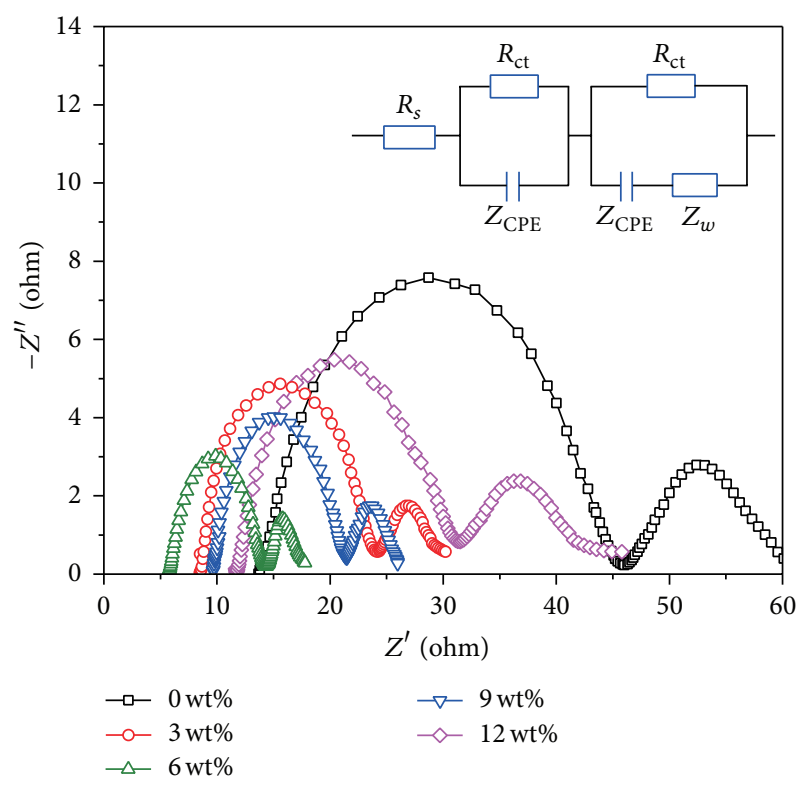

FIGURE 4: Nyquist diagram of thin-layer cells with various contents of VMT and the inset shows the equivalent circuit.

TABLE 1: The results for the $R_{\mathrm{ct}}$ and corresponding $\sigma$ of the iodidebased gel electrolytes with various contents of VMT.

\begin{tabular}{lccc}
\hline VMT $(\mathrm{wt} \%)$ & $R_{\mathrm{ct}}(\Omega)$ & $R_{s}(\Omega)$ & $\sigma\left(10^{-4} \mathrm{~S} \mathrm{~cm}^{-1}\right)$ \\
\hline 0 & 32.04 & 13.69 & 11.41 \\
3 & 15.05 & 9.11 & 17.15 \\
6 & 8.35 & 5.75 & 27.17 \\
9 & 13.47 & 7.85 & 19.91 \\
12 & 19.64 & 11.63 & 13.44 \\
\hline
\end{tabular}

in Figure 4. The equivalent circuit is shown as the inset of Figure 4. Each curve is composed of two semicircles. The one in the high frequency region represents the charge transfer resistance $\left(R_{\mathrm{ct}}\right)$ of Pt/electrolyte interface, and the other one in the low frequency region relates to the Warburg impedance $\left(Z_{w}\right)$ [8]. $R_{s}$ is the ohmic serial resistance and $Z_{\mathrm{CPE}}$ is the impedance of electrical double layer. Based on the equivalent circuit, the fitting data of the charge transfer resistance $\left(R_{\mathrm{ct}}\right)$ and the ohmic serial resistance $\left(R_{s}\right)$ were obtained. Then the ion conductivity of the electrolyte $(\sigma)$ can be obtained from the equation $\sigma=l /\left(R_{s} a\right)$ [4], where $a$ are $l$ are the active area of the electrodes (here $a=0.16 \mathrm{~cm}^{2}$ ) and the distance between electrodes (here $l=0.25 \mu \mathrm{m}$ ), respectively. The results for the $R_{\mathrm{ct}}$ values and $R_{\mathrm{s}}$ values and corresponding $\sigma$ values of iodide-based gel electrolytes with various contents of VMT are summarized in Table 1.

As shown in Figure 4 and Table 1 , the $R_{\text {ct }}$ values and the $R_{s}$ values of the cells decrease markedly and the corresponding $\sigma$ values increase with adding VMT up to $6 \mathrm{wt} \%$. Here, VMT as dispersed second phase insulating particles affected drastically the conductivities of composite iodidebased gel electrolytes. Quite a few works [16, 17] reported the effect of dispersed second phase particles on the ionic
TABLE 2: The photovoltaic parameters of the DSSCs with various contents of VMT.

\begin{tabular}{lcccc}
\hline VMT $(\mathrm{wt} \%)$ & $J_{\mathrm{sc}}\left(\mathrm{mA} \mathrm{cm}^{-2}\right)$ & $V_{\mathrm{oc}}(\mathrm{V})$ & $\mathrm{FF}$ & $\eta(\%)$ \\
\hline 0 & 5.08 & 0.62 & 0.54 & 1.70 \\
3 & 9.07 & 0.64 & 0.53 & 3.07 \\
6 & 9.77 & 0.67 & 0.59 & 3.89 \\
9 & 8.53 & 0.66 & 0.55 & 3.10 \\
12 & 7.15 & 0.64 & 0.53 & 2.43 \\
\hline
\end{tabular}

conduction. When adding the insulating phase in the ionconductive phase, ionic conductivity will first increase and then decrease. Nan developed an improved and simple selfconsistent effective-medium theory to explain the effect [18]. It has now become widely accepted that the enhancement effect of conductivity is related to creating highly conductive paths along the interfaces between the electrolyte matrix and the second phase grains [18]. The highly conductive paths can be an interfacial layer with high concentrations of defects, a space charge layer, and/or an absorbed water layer. VMT has a layered structure with a large surface area, which means there is enough interface to create conductive paths. When the content of VMT is $6 \mathrm{wt} \%$, the minimum $R_{\mathrm{ct}}$ value of $8.35 \Omega$ and the minimum $R_{s}$ value of $5.75 \Omega$ are obtained, corresponding with the maximum $\sigma$ value of $27.17 *$ $10^{-4} \mathrm{~S} \mathrm{~cm}^{-1}$. While the content of VMT is over $6 \mathrm{wt} \%$, the inert second phase particles directly contact each other to form continuum percolation net clusters, which tends to limit ion movement and decrease the conductivity $[17,18]$, and, as a result, the $R_{\mathrm{ct}}$ values and the $R_{\mathrm{s}}$ value increase and the $\sigma$ values decrease markedly.

3.3. The Influence of VMT on the Photovoltaic Conversion Efficiency. Figure 5(a) is the $J-V$ curves of thin-layer cells with various VMT contents. The results for short-circuit current density $\left(J_{\text {sc }}\right)$, open circuit potential $\left(V_{\text {oc }}\right)$, fill factor $(\mathrm{FF})$, and conversion efficiency $(\eta)$ of the DSSCs with different additions of VMT are summarized in Table 2. The DSSCs with the electrolytes adding VMT show a higher open circuit potential $\left(V_{\mathrm{oc}}\right)$ and significantly higher short current density $\left(J_{\mathrm{sc}}\right)$ than that without adding VMT. $V_{\mathrm{oc}}$ and $J_{\mathrm{sc}}$ increase first and then decrease with the increase of VMT contents. In order to study the influence of electrolytes with adding various contents of VMT on the above photoelectric properties, the dark current density-voltage curves of the DSSCs with various contents of VMT are shown in Figure 5(b). It can be easily found that the dark current density decreases when adding the VMT. As the content of VMT increases to $6 \mathrm{wt} \%$, the dark current density of the DSSC is suppressed to a minimum and increases quickly as the content of VMT further increases over $6 \mathrm{wt} \%$ to $12 \mathrm{wt} \%$.

The change in both $V_{\mathrm{oc}}$ and $J_{\mathrm{sc}}$ of the DSSCs is related to the dark current density. The enhanced $V_{o c}$ is due to the suppression of the dark current in the $\mathrm{TiO}_{2}$ /electrolyte interface. The fact that the onset of the dark current of DSSCs occurs at the higher forward bias indicates the lower $I_{3}^{-}$ reduction rate $\left(k_{\text {et }}\right)[9,19]$. The decrease of $I_{3}^{-}$reduction rate 


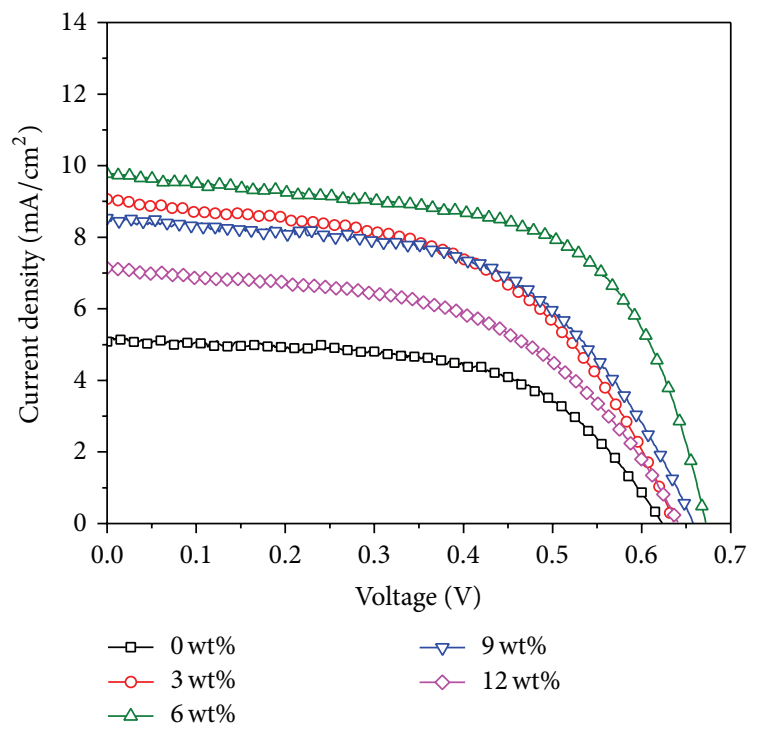

(a)

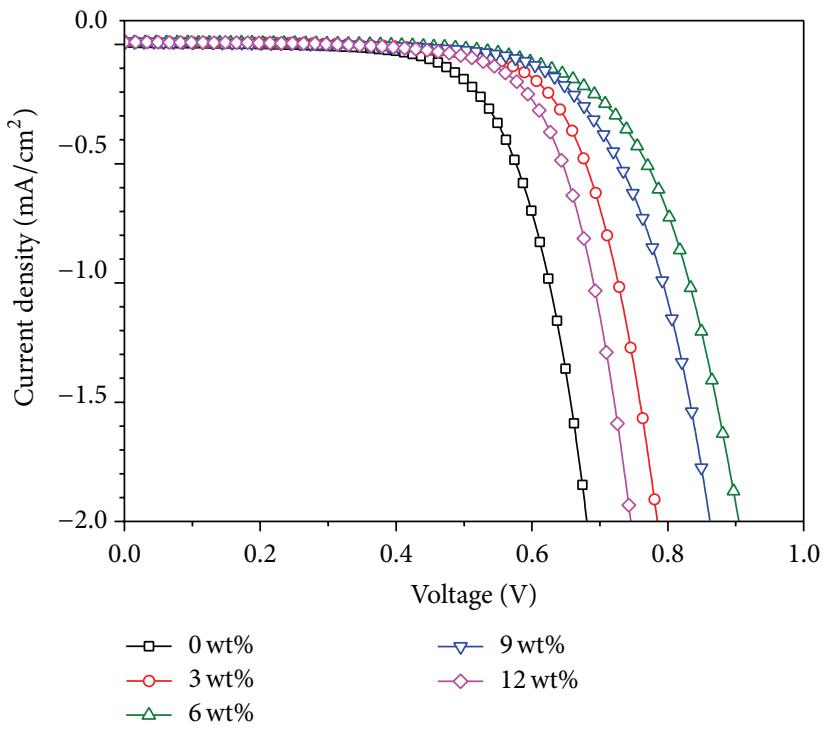

(b)

FIgURE 5: The $J-V$ curves of DSSCs with composite electrolytes containing various contents of VMT (a) under simulated AM 1.5 solar spectrum irradiation at $100 \mathrm{~mW} \mathrm{~cm}^{-2}$; (b) in the dark.

will lead to an increase of $V_{\mathrm{oc}}$ according to the following equation [19]:

$$
V_{\mathrm{oc}}=\frac{k T}{e} \ln \left(\frac{I_{\mathrm{inj}}}{n_{\mathrm{cb}} k_{\mathrm{et}}\left[I_{3}^{-}\right]}\right) \text {, }
$$

where $I_{\mathrm{inj}}, n_{\mathrm{cb}}$, and $k_{\mathrm{et}}$ are the flux of charge originating from sensitized injection related to the electron back transfer rate, the concentration of electrons at the $\mathrm{TiO}_{2}$ surface, and the rate constants for $I_{3}^{-}$reduction, respectively. As shown in Figure 5(b), the onset of the dark current of DSSCs occurs at $227,335,378,325$, and $319 \mathrm{mV}$ with various electrolytes adding $0 \mathrm{wt} \%, 3 \mathrm{wt} \%, 6 \mathrm{wt} \%$, $9 \mathrm{wt} \%$, and $12 \mathrm{wt} \%$ of $\mathrm{VMT}$, respectively. The higher onset voltage value of the dark current of DSSCs with adding VMT than that without adding VMT reveals that VMT can efficiently suppress the dark reaction to obtain higher $V_{\mathrm{oc}}$. On the other hand, the $J_{\mathrm{sc}}$ of DSSCs is also associated with the dark current, which can be given by the equation $J_{\text {sc }}=J_{\text {inj }}-J_{\text {rec}}$, where $J_{\text {inj }}$ and $J_{\text {rec }}$ are the electron injection current density and the recombination current density, respectively [20]. The electron injection current density should be constant since all the DSSCs have the same electrodes and experimental conditions. The recombination current mainly manifests as the dark current, so the recombination current density has similar variation trend with the dark current density [21]. Consequently $J_{\mathrm{sc}}$ increases with the decrease of the dark current density. As a consequence, proper addition of VMT can improve both $J_{\mathrm{sc}}$ and $V_{\mathrm{oc}}$ of the DSSC, and the best ratio is about $6 \mathrm{wt} \%$ of VMT. When the content of VMT is $6 \mathrm{wt} \%$, the conversion efficiency $(\eta)$ is up to the maximum of $3.89 \%$, which is more than two times greater than that without adding VMT. While the content of VMT is over $6 \mathrm{wt} \%$, the conversion efficiency $(\eta)$ decreases quickly.

\section{Conclusions}

In summary, we prepared a quasi-solid-state composite electrolyte by adding layered vermiculite (VMT) powder into the iodide-based electrolyte including PC, TBP, and PEO600,000 . Electrochemical analysis was done on the DSSCs with various electrolytes adding different contents of VMT. The results showed that VMT as a dispersed second phase insulating particles affected drastically the conductivities of composite electrolytes. The reduction of the dark current density with adding VMT indicated that the $J_{\text {sc }}$ and $V_{\mathrm{oc}}$ increased with the addition of appropriate amount of VMT, compared to DSSCs without VMT. When the content of VMT reached $6 \mathrm{wt} \%$, the conversion efficiency $(\eta)$ was maximized to $3.89 \%$, which was more than two times greater than that without addition of the VMT.

\section{Conflict of Interests}

The authors declare that there is no conflict of interests regarding the publication of this paper.

\section{Acknowledgments}

This work was supported by Natural Science Foundation of China (51272035, 51272037, and 51362026), International Cooperation MOST-JST Program Fund (no. 2010DFA61410), The Project of International Cooperation of the Ministry of Science and Technology of China (no. 2011DFA50530), 
and Scientific Research Project of Guangdong (no. 2012B091000015).

\section{References}

[1] B. O'Regan and M. Grätzel, "A low-cost, high-efficiency solar cell based on dye-sensitized colloidal $\mathrm{TiO}_{2}$ films," Nature, vol. 353, no. 6346, pp. 737-740, 1991.

[2] K. Tennakone, G. K. R. Senadeera, D. B. R. A. De Silva, and I. R. M. Kottegoda, "Highly stable dye-sensitized solid-state solar cell with the semiconductor $4 \mathrm{CuBr} 3 \mathrm{~S}_{(}\left(\mathrm{C}_{4} \mathrm{H}_{9}\right)_{2}$ as the hole collector," Applied Physics Letters, vol. 77, no. 15, pp. 2367-2369, 2000.

[3] C. S. Karthikeyan, H. Wietasch, and M. Thelakkat, "Highly efficient solid-state dye-sensitized $\mathrm{TiO}_{2}$ solar cells using donorantenna dyes capable of multistep charge-transfer cascades," Advanced Materials, vol. 19, no. 8, pp. 1091-1095, 2007.

[4] X. Chen, Q. Li, J. Zhao et al., "Ionic liquid-tethered nanoparticle/poly(ionic liquid) electrolytes for quasi-solid-state dyesensitized solar cells," Journal of Power Sources, vol. 207, pp. 216221, 2012.

[5] P. Wang, S. M. Zakeeruddin, J. E. Moser, M. K. Nazeeruddin, T. Sekiguchi, and M. Grätzel, "A stable quasi-solid-state dyesensitized solar cell with an amphiphilic ruthenium sensitizer and polymer gel electrolyte," Nature Materials, vol. 2, no. 6, pp. 402-407, 2003.

[6] K.-M. Lee, P.-Y. Chen, C.-P. Lee, and K.-C. Ho, "Binary roomtemperature ionic liquids based electrolytes solidified with $\mathrm{SiO}_{2}$ nanoparticles for dye-sensitized solar cells," Journal of Power Sources, vol. 190, no. 2, pp. 573-577, 2009.

[7] C.-P. Lee, K.-M. Lee, P.-Y. Chen, and K.-C. Ho, "On the addition of conducting ceramic nanoparticles in solvent-free ionic liquid electrolyte for dye-sensitized solar cells," Solar Energy Materials and Solar Cells, vol. 93, no. 8, pp. 1411-1416, 2009.

[8] C.-P. Lee, L.-Y. Lin, R. Vittal, and K.-C. Ho, "Favorable effects of titanium nitride or its thermally treated version in a gel electrolyte for a quasi-solid-state dye-sensitized solar cell," Journal of Power Sources, vol. 196, no. 3, pp. 1665-1670, 2011.

[9] N. Wang, H. Lin, J. Li, and X. Li, "Improved quasi-solid dye-sensitized solar cells by composite ionic liquid electrolyte including layered $\alpha$-zirconium phosphate," Applied Physics Letters, vol. 89, no. 19, Article ID 194104, 2006.

[10] H. He, J. Zhu, N. Wang, F. Luo, and K. Yang, "Composite gel polymer electrolytes containing layered $\mathrm{Mg}$-Al hydrotalcite for quasi-solid dye-sensitized solar cells," Journal of the Electrochemical Society, vol. 161, pp. H17-H20, 2014.

[11] M. V. Smalley, H. L. M. Hatharasinghe, I. Osborne, J. Swenson, and S. M. King, "Bridging flocculation in vermiculite-PEO mixtures," Langmuir, vol. 17, no. 13, pp. 3800-3812, 2001.

[12] L. Zang, J. Luo, J. Guo, H. Liu, and J. Ru, "Preparation and characterization of poly(ethylene glycol)/organo- vermiculite nanocomposite polymer electrolytes," Polymer Bulletin, vol. 65, no. 7, pp. 669-680, 2010.

[13] A. N. Nguyen, L. Reinert, J. M. Lévêque et al., "Preparation and characterization of micron and submicron-sized vermiculite powders by ultrasonic irradiation," Applied Clay Science, vol. 72, pp. 9-17, 2013.

[14] Y. Ren, Z. Zhang, S. Fang, M. Yang, and S. Cai, "Application of PEO based gel network polymer electrolytes in dye-sensitized photoelectrochemical cells," Solar Energy Materials and Solar Cells, vol. 71, no. 2, pp. 253-259, 2002.
[15] N. Papageorgiou, W. F. Maier, and M. Grätzel, "An iodine/triiodide reduction electrocatalyst for aqueous and organic media," Journal of the Electrochemical Society, vol. 144, no. 3, pp. 876-884, 1997.

[16] C. C. Liang, "Conduction characteristics of the lithium iodidealuminum oxide solid electrolytes," Journal of the Electrochemical Society, vol. 120, no. 10, pp. 1289-1292, 1973.

[17] C.-W. Nan, L. Fan, Y. Lin, and Q. Cai, "Enhanced ionic conductivity of polymer electrolytes containing nanocomposite $\mathrm{SiO}_{2}$ particles," Physical Review Letters, vol. 91, no. 26, pp. 2661041-2661044, 2003.

[18] C.-W. Nan, "Physics of inhomogeneous inorganic materials," Progress in Materials Science, vol. 37, no. 1, pp. 1-116, 1993.

[19] M. K. Nazeeruddin, A. Kay, I. Rodicio et al., "Conversion of light to electricity by cis-X2bis $\left(2,2^{\prime}\right.$-bipyridyl- $4,4^{\prime}$ dicarboxylate)ruthenium(II) charge-transfer sensitizers ( $\mathrm{X}=$ $\mathrm{Cl}-, \mathrm{Br}-, \mathrm{I}-, \mathrm{CN}-$, and SCN-) on nanocrystalline $\mathrm{TiO}_{2}$ electrodes," Journal of the American Chemical Society, vol. 115, no. 14, pp. 6382-6390, 1993.

[20] L. Y. Chen and Y. T. Yin, "The influence of length of onedimensional photoanode on the performance of dye-sensitized solar cells," Journal of Materials Chemistry, vol. 22, no. 47, pp. 24591-24596, 2012.

[21] K. Guo, M. Li, X. Fang et al., "Preparation and enhanced properties of dye-sensitized solar cells by surface plasmon resonance of Ag nanoparticles in nanocomposite photoanode," Journal of Power Sources, vol. 230, pp. 155-160, 2013. 

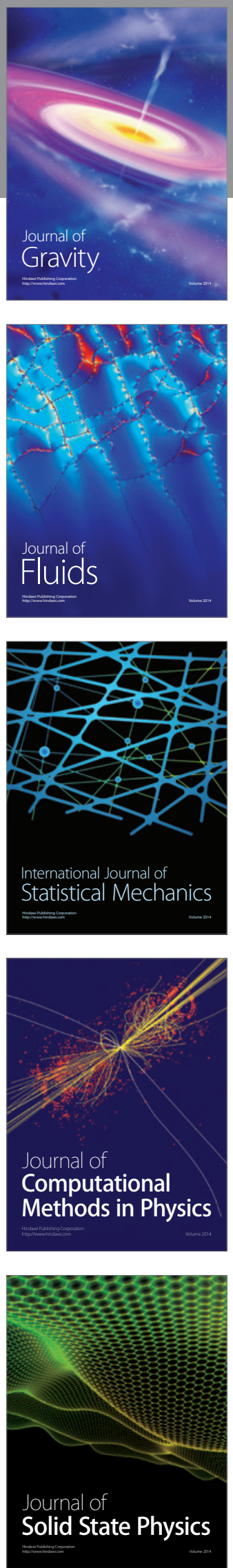

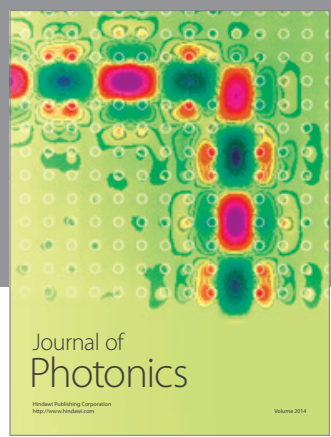

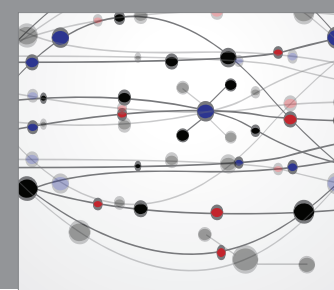

The Scientific World Journal

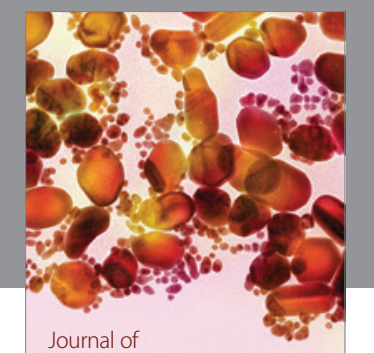

Soft Matter
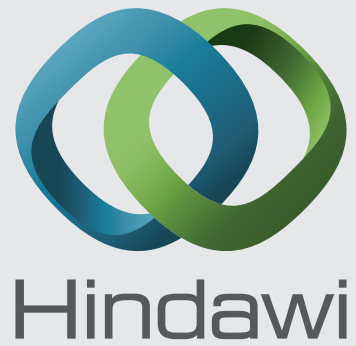

Submit your manuscripts at

http://www.hindawi.com
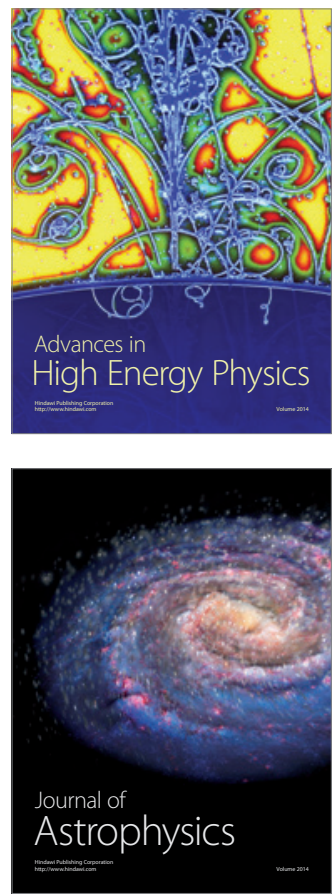
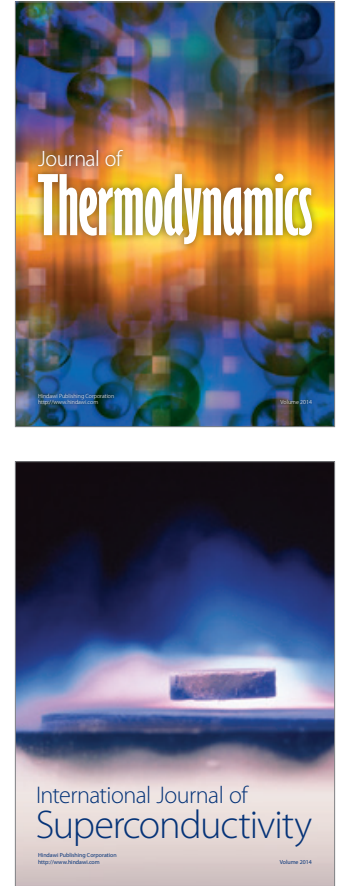
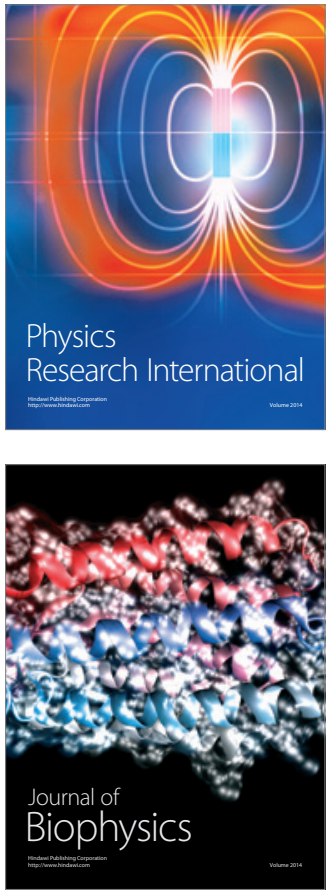
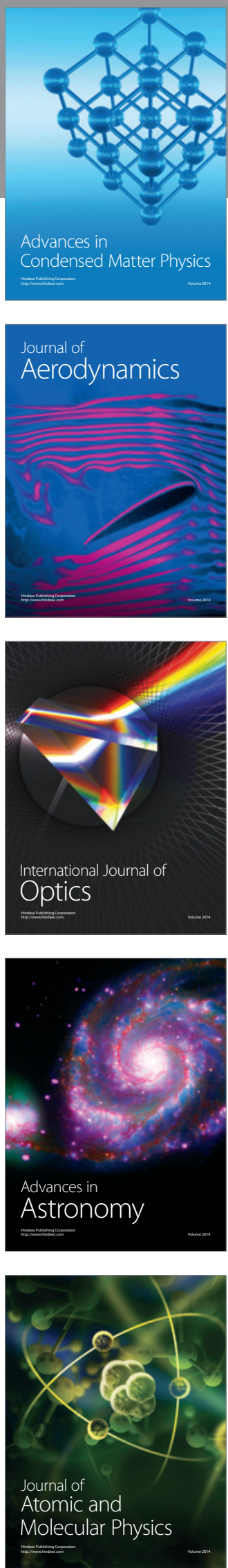